\title{
The Length and Density of Prickles on Zanthoxylum ailanthoides (Rutaceae): A Comparison of Japanese Islands with Different Sika Deer Browsing Pressures
}

\author{
Shogo Takei ${ }^{1}$, Kazuhiro Yoshioka ${ }^{1}$, Satoru Yamada ${ }^{1}$, Hiroshi Hayakawa ${ }^{1}$, Jun Yokoyama ${ }^{2}$, \\ Katsura Ito ${ }^{1}$, Shin-Ichi Tebayashi ${ }^{1}$, Ryo Arakawa ${ }^{1}$, Tatsuya Fukuda ${ }^{{ }^{*}}$ \\ ${ }^{1}$ Faculty of Agriculture, Kochi University, Kochi, Japan; ${ }^{2}$ Faculty of Science, Yamagata University, Yamagata, Japan. \\ Email: thukuda@kochi-u.ac.jp
}

Received December $6^{\text {th }}, 2013$; revised January $11^{\text {th }}, 2014$; accepted January $24^{\text {th }}, 2014$

Copyright (C) 2014 Shogo Takei et al. This is an open access article distributed under the Creative Commons Attribution License, which permits unrestricted use, distribution, and reproduction in any medium, provided the original work is properly cited. In accordance of the Creative Commons Attribution License all Copyrights (c) 2014 are reserved for SCIRP and the owner of the intellectual property Shogo Takei et al. All Copyright (C) 2014 are guarded by law and by SCIRP as a guardian.

\section{ABSTRACT}

To determine the effects of sika deer (Cervus nippon) browsing on the physical defences of the Japanese pricklyash "Zanthoxylum ailanthoides Sieb. et Zucc." (Rutaceae), we compared the length and density of prickles on Japanese islands which were under different browsing pressures. We measured the length and density of prickles on the midribs, leaf rachis, and stems. We found that the prickles of $Z$. ailanthoides on Kashima island were not significantly longer or at higher densities than those in the neighbouring areas; the longest pickles at the highest densities were found on Akune island. The density of sika deer on Akune (ca. $\left.520-600 / \mathrm{km}^{2}\right)$ was higher than that on Kashima (ca. $38.5 / \mathrm{km}^{2}$ ), and consequently, Akune was under greater browsing pressure. Our results suggest that the increased length and density of prickles on Akune is a response by Z. ailanthoides to the high density of sika deer found on the island.

\section{KEYWORDS}

Deer; Defence; Density; Herbivore; Island; Length; Sika

\section{Introduction}

Plants have developed numerous physical and chemical defences against herbivores. Such defences are considered beneficial because they ultimately reduce herbivory, and increase plant fitness [1]. The physical defences of plants are required to withstand abiotic factors, such as wind damage, and biotic factors, such as herbivory. The Japanese sika deer (Cervus nippon) eats a wide variety of plants and is a gregarious species. Consequently the effects of sika deer on plant communities are increasing in the forests and alpine ecosystems of Japan [2], and local increases in sika deer numbers compound these effects [3-5]. Indeed, sika deer have a large impact on agricultural and forested vegetation in Japan [2], and on the islands of southern Japan, are important in seed dispersal, particularly the small seeds of graminoids [6,7].

*Corresponding author.
The heavy browsing of sika deer has therefore altered the structure of some Japanese forests [2].

Prickles are thought to reduce the quantity of twigs or shoots eaten per unit of time by vertebrate herbivores by reducing bite size or biting rate [8-10], and are a defence primarily against mammalian herbivores [11]. Interestingly, some studies indicate that plants have developed long prickles as a defence against heavy browsing by sika deer on small Japanese islands. For example, Kinkazan island (32'57"N, 132'27"E; area: 959 ha), which is situated approximately $1 \mathrm{~km}$ off the Pacific coast of Honshu, has a high density of sika deer (ca. 63.2/ $\mathrm{km}^{2}$ ) [12]. As a result, Cirsium amplexifolium (Nakai) Kitam. var. muraii (Kitam.) Kitam. (Asteraceae) has a limited distribution on the island, and has longer prickles around its leaf edges and stems than those of C. amplexifolium var. amplexifolium, that occurs over a wide area of northern Honshu [13]. In addition, Kashima isl- 
and (32'57"N, 132'27"E; area: 45.1 ha) (Figure 1), which is located off southwest Shikoku, has a high density of sika deer (ca. 38.5/ $/ \mathrm{km}^{2}$ ) [14], and the prickles of Rubus sieboldii Blume (Rosaceae) are significantly longer and at higher densities than those in ungrazed neighbouring localities, based on comparative morphological analysis [15].

These results suggest that many other plant species may have developed long prickles under the high browsing pressure of sika deer, but which species in particular remains unknown.

On Kashima, several plant species exist that possess prickles [16]. Of these, Zanthoxylum ailanthoides Sieb. et Zucc. (Rutaceae) is a medium to large deciduous pioneer species that has pinnate leaves and conical prickles (Figure 2) and is found in Japan, Taiwan, Korea, China, and other parts of southeast Asia [13]. Further, it is one of the avoided plant species because of its prickles, which is a form of anti-herbivore defence [14]. This species may not only possess physical defences against herbivores, but also chemical defences, since it contains lignans, coumarins, quinolines, flavonoids, triterpenoids, and other substances [17]. However, this species is frequently damaged by sika deer on Mt. Kasugayama (ca. $\left.950 / \mathrm{km}^{2}\right)[4,18]$. Therefore, the chemical defences of this species may be most effective against insect rather than deer attack, suggesting that it is possible to evaluate the effects of sika deer browsing by measuring the characteristics of the plants' physical defences (i.e. prickles) as has been carried out for other plant species.

Kamijo et al. (2001) [19] conducted a comparative study of seedling morphology of $Z$. ailanthoides on the

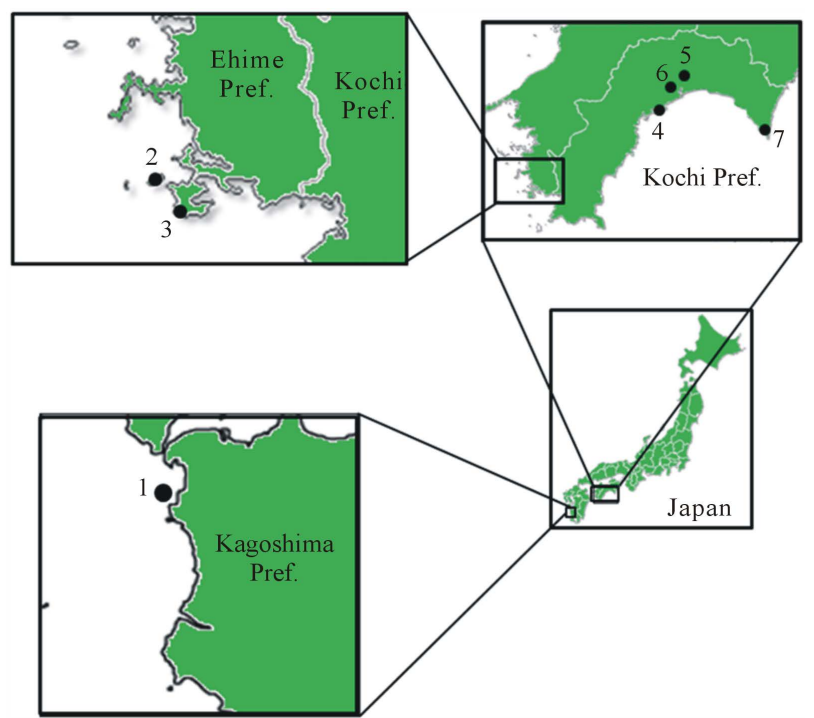

Figure 1. Sampling sites in this study. 1: Akune island; 2: Kashima island; 3: Komo Cape; 4: Yokonami; 5: Kurotaki; 6: Hitsuzan; and 7: Muroto.
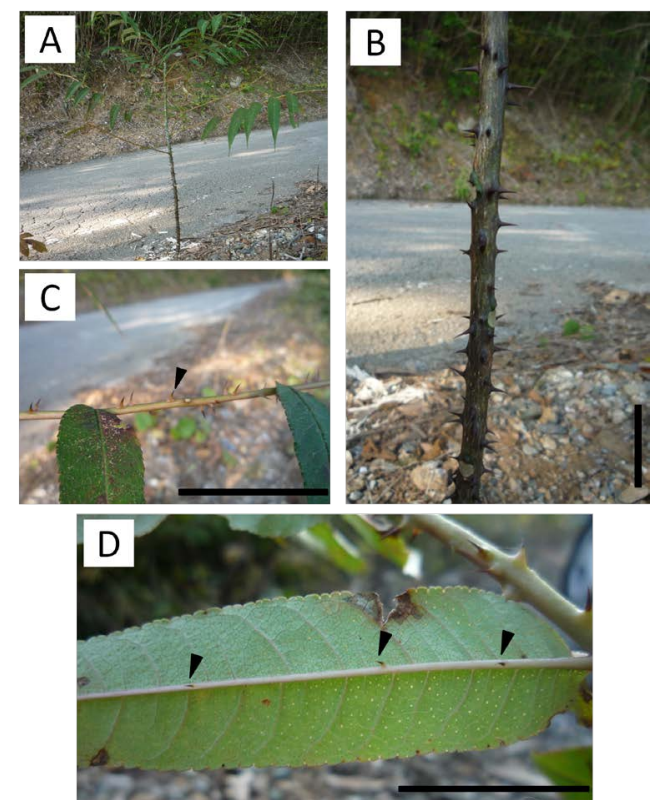

Figure 2. Zanthoxylum ailanthoides (photographs were taken at Kurotaki, Kochi Prefecture). (A) Zanthoxylum ailanthoides; (B) Stem; (C) Leaf rachis; (D) Midrib. Bar = 1 cm. Arrowheads indicate prickles.

Izu islands, where there are no sika deer, and the Izu Peninsula, where sika deer are present. The percentage dry weight of prickles was lower on the $Z$. ailanthoides found on the Izu islands than those of the $Z$. ailanthoides found on the Izu Peninsula [19]. In addition, a nonprickle form, Z. ailanthoides var. ailanthoides f. espinosum Yonek, was found on Nii-jima island, which is one of the Izu islands [19]. It might therefore be possible for $Z$. ailanthoides to grow with no prickles, or few prickles, where sika deer are absent. Kamijo et al. (2001) [19] measured the relative weight of prickle to plant size using germinated seedlings derived from only one parent per population, under nursery conditions. However, no studies have been conducted that have used large numbers of samples derived from different parents, and grown under natural conditions with heavy browsing by sika deer.

In this study, we investigated whether $Z$. ailanthoides plants on Kashima have also developed long prickles to resist browsing by sika deer, as have $R$. sieboldii plants. The flora of Akune island (130'10"E 32'01"N) is similar to that of Kashima [14,20], and includes Z. ailanthoides. Akune is a small island (29.3 ha) off the southwest of Kyushu (Figure 1), and has a high density of sika deer (ca. $520-600 / \mathrm{km}^{2}$ ) [21,22]. It is possible that the prickles of Z. ailanthoides on Akune are also long as a defence against sika deer. The density of sika deer differs between Kashima and Akune, therefore the length and density of prickles of $Z$. ailanthoides may differ between 
the islands. The aim of this study was to compare the prickle characteristics of Z. ailanthoides on Akune and Kashima with those of neighbouring areas.

\section{Materials and Methods}

Z. ailanthoides samples were collected from Kashima and Akune (that were heavily browsed by sika deer), and 5 areas close to Kashima (Komo Cape, Yokonami, Kurotaki, Hitsuzan, and Muroto) in 2012 and 2013 (Figure 1, Table 1). The height of individual plants included was less than $1.5 \mathrm{~m}$, which is the maximum height reached by sika deer. To measure prickle length and density on the midribs and leaf rachis of $Z$. ailanthoides, five fully expanded leaves from the middle of each plant were collected. The mean length and density of prickles were calculated based on measuring the length and density of 5 prickles per leaf. The mean length of prickles on a stem was calculated as the mean length of 5 prickles from 10 locations near the middle of the stem. Prickle density on stems was measured by counting the number of prickles per square section of the stem surface area at 10 locations on each plant. We measured leaf area, tree diameter at the base, and plant size, and analysed the prickle traits in comparison with the other traits. All statistical analyses were performed using SPSS Statistics 19 (IBM SPSS, Chicago, Illinois).

\section{Results and Discussion}

We analysed the length and density of prickles on the midribs, leaf rachis, and stem surfaces of $Z$. ailanthoides on Kashima and neighbouring areas, and on Akune (Table 2). The length and density of $Z$. ailanthoides prickles on Kashima were similar to those in the neighbouring areas (Figure 3, Table 2), suggesting that the grazing pressure of sika deer did not affect prickle characteristics on this island. The Akune population had the longest prickles, and the highest densities of prickles, of all the populations analysed (Figure 3, Table 2). These results suggest that $Z$. ailanthoides prickles on Akune had increased in length and density to counteract heavy browsing by sika deer. We did not find any relationships between prickle traits and the other traits measured (data

Table 1. Sampling sites in this study.

\begin{tabular}{|c|c|c|c|c|c|}
\hline Location name & $\begin{array}{c}\text { Location } \\
\text { no. }\end{array}$ & $\begin{array}{l}\text { Number of } \\
\text { Individuals }\end{array}$ & Location & \multicolumn{2}{|c|}{ Latitude and longitude } \\
\hline Akune Island & 1 & 30 & Kagoshima Prefecture, Akune City & $\mathrm{N} 32^{\circ} 01^{\prime}$ & E $130^{\circ} 10^{\prime}$ \\
\hline $\begin{array}{l}\text { Kashima } \\
\text { Island }\end{array}$ & 2 & 15 & Ehime Prefecture, Minamiuwa-Gun, Ainan-Cho Kashima & N $32^{\circ} 56^{\prime}$ & E $132^{\circ} 27^{\prime}$ \\
\hline Komo Cape & 3 & 30 & Ehime Prefecture, Minamiuwa-Gun, Ainan-Cho Komo & N $32^{\circ} 54^{\prime}$ & E $132^{\circ} 28^{\prime}$ \\
\hline Yokonami & 4 & 30 & Kochi Prefecture, Susaki City, Uranouchi Yokonami & N $33^{\circ} 25^{\prime}$ & E $133^{\circ} 21^{\prime}$ \\
\hline Kurotaki & 5 & 30 & Kochi Prefecture, Nankoku City, Kurotaki & N $33^{\circ} 39^{\prime}$ & E $133^{\circ} 36^{\prime}$ \\
\hline Hitsuzan & 6 & 30 & Kochi Prefecture, Kochi City, Hitsuzan-Cho Hitsuzan & N $33^{\circ} 33^{\prime}$ & E $133^{\circ} 31^{\prime}$ \\
\hline Muroto & 7 & 30 & $\begin{array}{c}\text { Kochi Prefecture, Muroto City, Murotomisaki-Cho } \\
\text { Muroto }\end{array}$ & N $33^{\circ} 15^{\prime}$ & E $134^{\circ} 10^{\prime}$ \\
\hline
\end{tabular}

Table 2. Morphological measurements (average \pm standard deviation) of Zanthoxylum ailanthoides.

\begin{tabular}{|c|c|c|c|c|c|c|c|}
\hline Trait & Akune Island & Kashima Island & Komo Cape & Yokonami & Kurotaki & Hitsuzan & Muroto \\
\hline \multicolumn{8}{|l|}{ Midrib prickles } \\
\hline Density $\left(\mathrm{N} / \mathrm{cm}^{2}\right)$ & $3.99 \pm 1.14 \mathrm{a}$ & $1.51 \pm 0.20 \mathrm{~b}$ & $0.83 \pm 0.06 \mathrm{~b}$ & $0.16 \pm 0.02 b$ & $0.22 \pm 0.03 \mathrm{~b}$ & $0.35 \pm 0.04 \mathrm{~b}$ & $0.48 \pm 0.04 b$ \\
\hline \multicolumn{8}{|l|}{ Rachis prickles } \\
\hline Length (mm) & $4.68 \pm 0.16 \mathrm{a}$ & $3.50 \pm 0.25$ bc & $3.12 \pm 0.12 \mathrm{c}$ & $1.91 \pm 0.11 \mathrm{~d}$ & $3.22 \pm 0.09 \mathrm{c}$ & $2.06 \pm 0.07 \mathrm{~d}$ & $4.14 \pm 0.15 \mathrm{ab}$ \\
\hline Density $\left(\mathrm{N} / \mathrm{cm}^{2}\right)$ & $1.36 \pm 0.37 \mathrm{a}$ & $0.67 \pm 0.11 \mathrm{ab}$ & $0.43 \pm 0.03 b$ & $0.15 \pm 0.03 b$ & $0.17 \pm 0.03 \mathrm{~b}$ & $0.21 \pm 0.02 \mathrm{~b}$ & $0.32 \pm 0.04 b$ \\
\hline \multicolumn{8}{|l|}{ Stem prickles } \\
\hline Length (mm) & $5.67 \pm 0.49 \mathrm{a}$ & $3.96 \pm 0.27 b$ & $3.75 \pm 0.16 b$ & $3.56 \pm 0.14 b$ & $4.65 \pm 0.51 b$ & $2.15 \pm 0.09 \mathrm{c}$ & $4.73 \pm 0.15 \mathrm{ab}$ \\
\hline Density $\left(\mathrm{N} / \mathrm{cm}^{2}\right)$ & $10.26 \pm 0.36 a$ & $8.85 \pm 0.44 b$ & $6.45 \pm 0.20 \mathrm{~cd}$ & $5.59 \pm 0.20$ de & $8.78 \pm 0.27 b$ & $4.71 \pm 0.14 \mathrm{e}$ & $6.91 \pm 0.22$ c \\
\hline
\end{tabular}

Values that have the same letter within a column indicate no significant difference at the $5 \%$ level (Tukey HSD test). 

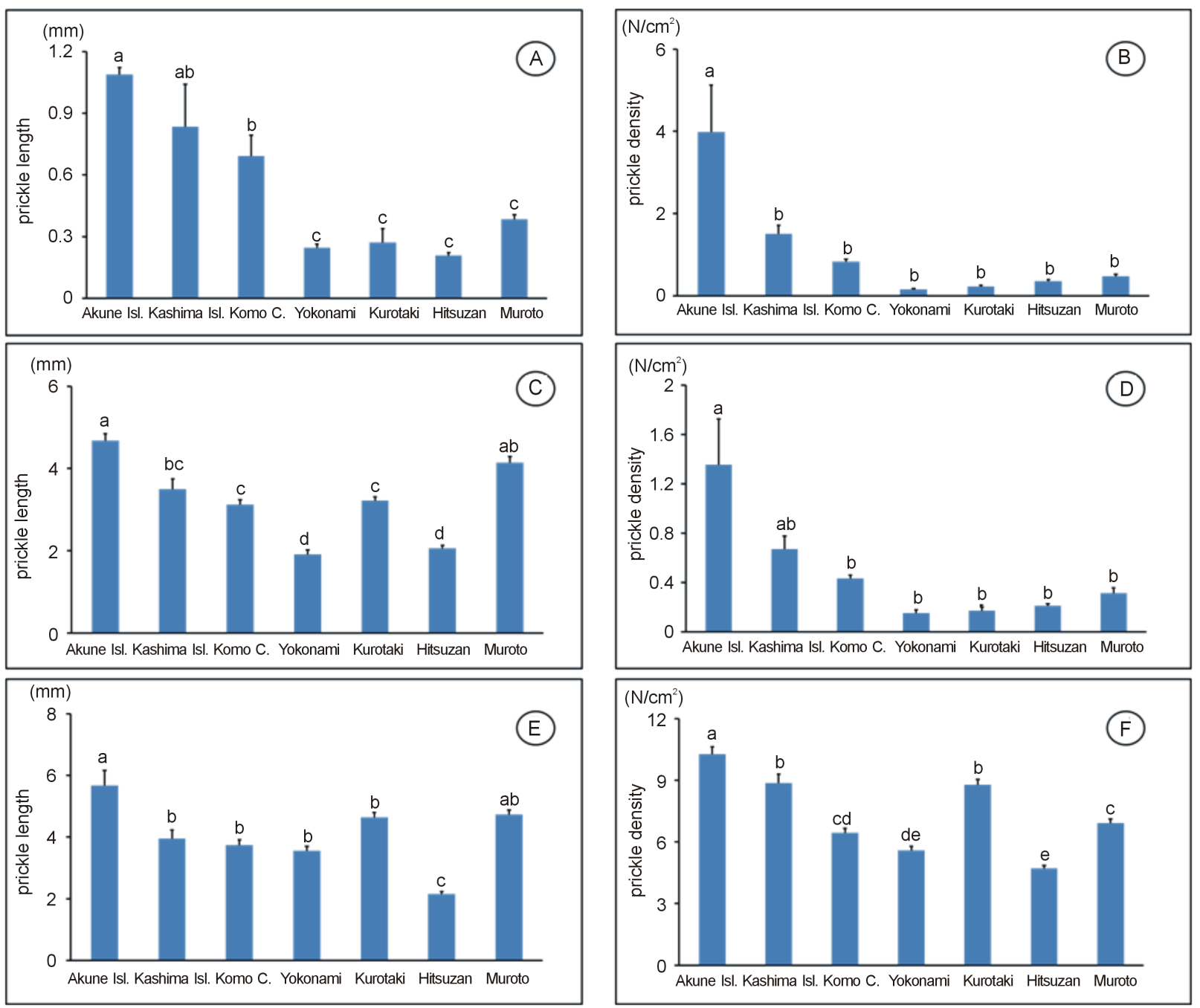

Figure 3. Morphological measurements of the prickles of Zanthoxylum ailanthoides. (A) Length on the midrib; (B) Density on the midribs; (C) Length on the leaf rachis; (D) Density on the leaf rachis; (E) Length on the stem; (F) Density on the stem.

not shown).

On Kashima, the prickles of $R$. sieboldii are significantly longer and at higher densities than those in neighbouring areas, probably as a response to relatively heavy browsing by sika deer [15], but we found that the prickles of $Z$. ailanthoides were of a similar length and at similar densities to those in neighbouring areas (Figure 3, Table 2). Further, why were the prickles of Z. ailanthoides on Kashima not longer and at higher densities than those in the adjacent regions. One possibility is that the prickle length and density of this species on Kashima were already sufficiently great to inhibit browsing by sika deer, and there was no necessity for the plant to develop longer prickles at higher densities. The prickle length of $Z$. ailanthoides was longer than that of $R$. sieboldii in the areas with low densities of sika deer [15], suggesting that prickles play an important role in a plant's defence against sika deer. Therefore, the prickle of them has physical defence to avoid browsing by sika deer in various evergreen forests including Kashima island.

In contrast to Kashima, the prickles of Z. ailanthoides on Akune were the longest and at the highest densities of all the regions included in the study, suggesting that such structural modifications could have occurred due to the high density of sika deer on the island. It is unknown why the Z. ailanthoides population of Akune had significantly the longest prickles; there was no significant difference in prickle length between the populations of Kashima and its neighbouring areas. The density of sika deer on Akune (ca. $520-600 / \mathrm{km}^{2}$ ) is approximately 15 times greater as that on Kashima (ca. $38.5 / \mathrm{km}^{2}$ ) $[14,21$, 22], suggesting that browsing pressure by sika deer on Akune is higher than on Kashima. Therefore, our results 
suggest that in response to the high browsing pressure of sika deer, the Z. ailanthoides population on Akune has developed longer prickles.

$R$. sieboldii plants with relatively long prickles have been reported on Kashima [15], but we could not find $R$. sieboldii on Akune, even though this species is found in areas close to the island [23]. We suggest that this species might be extinct on Akune due to overgrazing by sika deer, since there is greater browsing pressure on Akune compared to Kashima. Recent studies have shown that forest damage by sika deer in Japan has increased, and the deer is now regarded as the most damaging mammalian pest species [2]. Indeed, some areas of forest are so heavily browsed that forest regeneration is prevented [24]; it is possible that plant species with long prickles can be found in these forests.

From the results of the present study and those of Kamijo et al. (2001) [19], it is probable that populations of Z. ailanthoides develop more prickles under heavy sika deer browsing pressure, and fewer prickles under low sika deer browsing pressure. Interestingly, a non-prickle variety (Z. ailanthoides var. inerme Rehder et $\mathrm{E}$. $\mathrm{H}$. Wilson) that has thin leaves grows on the Ogasawara islands, which are oceanic islands without sika deer [25]. The non-prickled and prickled varieties of $Z$. ailanthoides could have evolved on oceanic islands and small coastal islands respectively due to differential selection pressures caused by sika deer grazing.

In this study, no significant relationships were found between prickle traits and the other plant traits. However, future studies should investigate the relationship between prickles and relative growth rate per year, as there may be a trade-off between the dry weight biomass of individual plants and their corresponding prickle weights in this species (see [19]).

\section{Acknowledgements}

We wish to thank Mr. Moriguchi Y. for providing useful comments concerning Kashima island, and Ohga K., Miyata H., Tsuchiya Y., Yoshimi Y., Muroi M., Isomoto S., Matsuyama K., Yokoyama N., Sunami T., Kumekawa Y., Kakimoto N., Matsui R., Inoue S., Uemoto C., Ozaki Y., Orito M., Kuribayashi S., Suzaki S., Fujiwara K., Minato Y., Miyake K. and Yamamoto F. for providing us with much needed assistance. This study was partly supported by Grant-in-Aid for Scientific Research from the Ministry of Education, Science and Culture of Japan (to TF and JY).

\section{REFERENCES}

[1] E. L. Simms and M. D. Rausher, "Cost and Benefits of Plant Resistance to Herbivory,” American Naturalist, Vol.
130, No. 4, 1987, pp. 570-581.

http://dx.doi.org/10.1086/284731

[2] S. Takatsuki, "Effects of Sika Deer on Vegetation in Japan: A Review,” Biological Conservation, Vol. 142, No. 9, 2009, pp. 1922-1929.

http://dx.doi.org/10.1016/j.biocon.2009.02.011

[3] R. M. A. Gill, "A Review of Damage by Mammals in North Temperate Forests: 3. Impact on Trees and Forests," Forestry, Vol. 65, No. 4, 1992, pp. 363-388. http://dx.doi.org/10.1093/forestry/65.4.363

[4] K. Shimoda, K. Kimura, M. Kanzaki and K. Yoda, “The Regeneration of Pioneer Tree Species under Browsing Pressure of Sika Deer in an Evergreen Oak Forest," Ecological Research, Vol. 9, No. 1, 1994, pp. 85-92. http://dx.doi.org/10.1007/BF02347245

[5] N. Akashi and T. Nakashizuka, "Effects of Bark Stripping by Sika Deer (Cervus nippon) on Population Dynamics of a Mixed Forest in Japan,” Forest Ecology and Managemen, Vol. 113, No. 1, 1999, pp. 75-82. http://dx.doi.org/10.1016/S0378-1127(98)00415-0

[6] S. Takatsuki, "Food Habits of Ungulates and Anti-Grazing Adaptation of Plants,” In: I. Washitani and T. Ogushi, Eds., Interrelations between Plants and Animals, Heibonsha, Tokyo, 1993, pp. 104-128.

[7] A. Yamashiro and T. Yamashiro, "Seed Dispersal by Kerama Deer (Cervus nippon keramae) on Aka Island, the Ryukyu Archipelago, Japan,” Biotropica, Vol. 38, No. 3, 2006, pp. 405-413. http://dx.doi.org/10.1111/i.1744-7429.2006.00158.x

[8] S. M. Cooper and N. Owen-Smith, "Effects of Plant Spinescence on Large Mammalian Herbivores,” Oecologia, Vol. 68, No. 3, 1986, pp. 446-455. http://dx.doi.org/10.1007/BF01036753

[9] G. E. Belovsky, O. J. Schmitz, J. B. Slade and T. J. Dawson, "Effects of Spines and Thorns on Australian Arid Zone Herbivores of Different Body Masses," Oecologia, Vol. 88, No. 4, 1991, pp. 521-528.

[10] G. E. Belovsky and O. J. Schmitz, "Plant Defenses and Optimal Foraging by Mammalian Herbivores,” Journal of Mammalogy, Vol. 75, No. 4, 1994, pp. 816-832. http://dx.doi.org/10.2307/1382464

[11] J. H. Gowda, "Spines of Acacia tortilis: What Do They Defend and How?” Oikos, Vol. 77, No. 2, 1996, pp. 279284. http://dx.doi.org/10.2307/1382464

[12] S. Takatsuki, "Group Size of Sika Deer in Relation to Habitat Type on Kinkazan Island," Japanese Journal of Ecology, Vol. 33, No. 4, 1983, pp. 419-425.

[13] T. Yamazaki, "Rutaceae,” In: Y. Satake, H. Hara, S. Watari and T. Tominari, Eds., Wild Flowers of Japan, Woody Plants I, Heibonsha, Tokyo, 1989, pp. 274-283.

[14] S. Takatsuki, "Ecological Studies on Effect of Sika Deer (Cervus nippon) on Vegetation III: The Vegetation of Iyo-Kashima Island, Southwestern Shikoku, with Reference to Grazing Effect of Sika Deer,” Ecological Review, Vol. 20, No. 1, 1982, pp. 15-29.

[15] S. Takei, K. Ohga, H. Hayakawa, J. Yokoyama, K. Ito, S. Tebayashi, R. Arakawa and T. Fukuda, "Comparative 
Analysis of the Prickles on Rubus sieboldii (Rosaceae) between Grazed and Ungrazed Areas in South-Western Shikoku, Japan,” Journal of Plant Studies, Vol. 2, No. 1, 2013, pp. 152-157. http://dx.doi.org/10.5539/jps.v2n1p152

[16] S. Hashigoe, "Flora of Kashima Island, Ehime Prefecture, Japan,” Biology in southern Ehime, Vol. 8, No. 1-2, 1995, pp. 22-32.

[17] J. J. Chen, C. Y. Chung, T. L. Hwang, J. F. Chen, W. H. Chang, Y. H. Ho and C. W. Lin, "New Alkaloid, Benzenoid, and Anti-Inflammatory Constituents from Zanthoxylum ailanthoides,” Planta Medica, Vol. 74, No. 9, 2008, p. 51. http://dx.doi.org/10.1055/s-0028-1084396

[18] Y. Maesako, "Sika Deer in Nara and the Future of the Evergreen Forest,” In: Y. Maesako Ed., The Warm-Temperate Evergreen Forest on Mt. Kasuzayama, Nakanishiya, Kyoto, 2013, pp. 228-244.

[19] T. Kamijo, K. Shimada, Y. Hoshino and T. Endo, “Comparative Study of Seedling Morphology of Zanthoxylum ailanthoides Sieb. Et Zucc. between Izu Islands and Izu Peninsula,” Bulletin of Tsukuba University Forest, Vol. 17, 2001, pp. 77-83.

[20] S. Takatsuki, "Ecological Studies on Effect of Sika Deer (Cervus nippon) on Vegetation III: The Vegetation of Akune Island, Kagoshima Prefecture, with Reference to Browsing and Grazing Effect of Sika Deer,” Ecological
Review, Vol. 19, No. 3, 1980, pp. 123-144.

[21] K. Ikeda and T. Iwamoto, “An Experiment in Estimating Sika Deer Density by the Pellet Count Method,” Mammalian Science, Vol. 44, No. 2, 2004, pp. 81-86. http://dx.doi.org/10.1046/j.1365-2664.2001.00584.x

[22] S. Kiyohisa, K. Sone, K. Hata and T. Koizumi, “Group Composition and Distribution of Japanese Sika Deer (Cervus nippon mageshimae) on Akune Island, Southern Japan,” Kyushu Journal of Forest Research, Vol. 58, 2005, pp. 188-190.

[23] N. Kido, "Botanical Research of the Island of Akuneohshima and the Area around Kuratsu Shrine on the Mainland," Bulletin of the International University of Kagoshima, Social Welfare, Vol. 28, No. 3, 2010, pp. 17-24.

[24] S. Takatsuki and T. Y. Ito, "Plants and Plant Communities on Kinkazan Island, Northern Japan, in Relation to Sika Deer Herbivory,” In: D. R. McCullough, S. Takatsuki and K. Kaji, Eds., Sika Deer: Biology and Management of Native and Introduced Populations, Springer, Tokyo, 2009, pp. 125-143. http://dx.doi.org/10.1007/978-4-431-09429-6_9

[25] K. Okutomi, T. Iseki, Y. Hioki, K. Kitayama and H. Sumihiro, "Vegetation of the Ogasawara Islands. Endemic Species and Vegetation of the Bonin Islands," Government, Tokyo, 1983, pp. 97-268. 